\title{
A study of the association between ISSR and RAPD markers and some agronomic traits in barley using a multiple regression analysis
}

\author{
Kianoosh Cheghamirza $^{1,2}$, Leila Zarei ${ }^{1,2}$ *, Ali ReZa ZebarJadi ${ }^{1,2}$, SAeID Jalali Honarmand ${ }^{1,2}$ \\ ${ }^{1}$ Department of Agronomy and Plant Breeding, Faculty of Science and Agricultural Engineering, Razi University, Kermanshah, Iran \\ ${ }^{2}$ Biotechnology Research Department for Drought Resistance, Razi University, Kermanshah, Iran
}

\begin{abstract}
The identification of associations between molecular markers and agronomic traits provides an excellent tool for indirect selection of traits of interest in a population. In this study, a stepwise regression analysis was used to estimate associations between inter-simple sequence repeat (ISSR) and random amplified polymorphic DNA (RAPD) markers with some agronomic traits in barley genotypes. Two-year average values for the measured traits under rain-fed and irrigation conditions were used for association analyzes. Thirty-one random RAPD and 20 ISSR primers were used in the study. The results of the stepwise regression analysis revealed significant associations between the traits and some of the studied loci. For all traits more than one informative marker was detected. A total of 88 informative markers, including 32 ISSR loci and 56 RAPD loci, were identified under both tested conditions. OPC4-1050, E17-400, and E19-1100 markers were associated with grain yield, biomass and spike length, respectively, under both tested conditions. These markers are relatively more reliable than other identified markers. Among the RAPD primers, special attention should be drawn to primer E17, which produced the highest number of fragments associated with traits such as biomass, plant height, spike length and number of seeds per spike, under rain-fed conditions. Moreover, the UBC856 ISSR primer revealed loci associated with grain yield, plant height and number of sterile spikelets per spike under irrigated conditions.
\end{abstract}

Key words: barley, informative markers, irrigation conditions, rain-fed conditions, stepwise regression

\section{Introduction}

Barley's (Hordeum vulgare L.) high value in the world's agriculture is confirmed by its high ranking among the most economically important crops: $4^{\text {th }}$ after wheat, corn and rice (Emam, 2007). In many parts of the world, drought is one of the main constraints on barley production. Due to the elaborated nature of drought tolerance, compared to other traits with lower complexity, e.g. quality or disease traits, breeding programs to improve drought tolerance could be carried out through selection for yield, which incorporate all the unknown factors important for increasing drought tolerance (Salem Farag, 2004). Yield is still used by breeders as the first criterion in the search for improvements in drought tolerance; however, it has a low heritability, especially when the plant is grown under drought stress conditions. Thus, an important strategy for improving drought tolerance is the selection for traits associated with drought tolerance (Chowdhry et al., 1999). The emergence of morphological traits is a function of the plant growth stage. These may be limited in number and are influenced by either environmental factors or the developmental stage of the plant (Stuber et al., 1999). These shortcomings led to the development of markers based on DNA polymorphisms, later superseded by DNA-based methods generating "fingerprints" which are distinctive patterns of DNA fragments typically subjected to high resolution gel electrophoresis and detected by staining or labeling (Schulman, 2007). RAPD markers can be defined as DNA polymorphisms produced due to "re-

\footnotetext{
* Corresponding author: Agricultural Faculty of Razi University, Department of Agronomy and Plant Breeding. Imam Khomeini Highway, Kermanshah, Iran, postal code: 6715685438; email: lzarei1360@yahoo.com
} 
arrangements or deletions at or between two close primer binding sites in the genome" (Welsh and McClelland, 1990; Williams et al., 1990). ISSR markers are alternatives to the RAPD technique, allowing higher annealing temperatures to be used, which ensures better reproducibility compared to RAPD. Repeat-anchored or non-anchored primers in the polymerase chain reaction (PCR) are used to amplify DNA sequences between two inverted SSRs (Zietkiewicz et al., 1994).

Finding an association between molecular markers and morphological traits provides an excellent tool for indirect selection of a trait of interest in a population. This has important applications in the study of relations between molecular markers and agronomic traits, some of which include: the collections of germplasms, the detection and analysis of potential in specific genotypes, the identification of desirable alleles and the validation of candidate markers linked to quantitative traits (Gebhardt et al., 2004). Although the mapping of Quantitative Trait Loci (QTLs) is well suited to the detection of genes associated with particular traits, it is labor-intensive (segregating a population is time-consuming) and costly (Rakshit et al., 2010). In order to overcome these limitations, a multiple regression analysis may be used, as it offers an appropriate method to identify markers associated with the trait. A multiple regression analysis is a statistical process for estimating the relationships between molecular markers as independent variables and morphological traits as dependent variables. It is a way to determine the coefficient of determination $\left(R^{2}\right)$, which gives the proportion of the variance (fluctuation) of the dependent variable that is predictable from the independent variable (Gomez and Gomez, 1984). A multiple regression analysis does not require a genetic map to be applied, and the method is quick, with multiple unlinked QTLs accounted for, problems with multiple testing reduced, and computer software readily available. However, a major disadvantage of the multiple regression approach to mapping QTLs is the requirement that the independent variable, i.e. the marker genotype, must be available for all records included in the analysis (Henshall and Goddard, 1995). According to the study by Firoozi et al. (2012), a multiple regression analysis of ISSR markers with agronomic traits allowed the identification of 43, 33 and 25 informative ISSR markers in irrigation conditions (control), and irrigated in either $2 / 3$ or $1 / 3$ total water requirement conditions, respectively.
Sofalian et al. (2008) reported that a Single Marker Analysis revealed that seven markers, constituting $27 \%$ of the determined phenotypic variance were linked to frost tolerance and five markers were linked to the heading time in bread wheat.

In this study, multiple regression was used to find the associations between ISSR and RAPD markers and some agronomic traits in barley genotypes.

\section{Materials and methods}

\section{Plant materials}

Twenty barley genotypes, including two varieties currently grown in Iran (WALFAJR and SARAROOD1) and 18 advanced lines, were used in this study. These were arbitrarily named 1-20 (Table 1 ). The pedigrees of genotypes are presented in Table 1.

\section{Field trials}

In a two-year field experiment carried out during the 2006-2007 and 2007-2008 cropping seasons at the experimental farm of the Agricultural Faculty of Razi University, Kermanshah, $\operatorname{Iran}\left(34^{\circ} 21^{\prime}, 47^{\circ} 9^{\prime}\right.$, 1319 m.a.s.l. $)$ two separate experiments were conducted under irrigation and rain-fed conditions. In the irrigation conditions, the plants were irrigated at three stages during the heading to flowering period, when more than $50 \%$ of the soil moisture content was depleted, whilst there was no additional irrigation under the rain-fed conditions. Subsamples of five plants in each plot were randomly selected at the maturity stage to measure the following traits:

- grain yield (GY): grain yields were determined in $\mathrm{kg} \cdot \mathrm{ha}^{-1}$ by harvesting plants grown in a one square meter area at the center of each plot;

- plant height (Phe): length of the main tiller was measured in centimeters from the soil surface to the tip of the main ear at maturity, excluding awns;

- spike length (SL): spike length was measured in centimeters;

- number of seeds per spike (NSPS): the number of seeds per spike was counted from the heads borne on the main tillers;

- number of sterile spikelets per spike (NSSP): the numbers of florets that had no grain at maturity;

- biomass (BIO): total dried above ground biomass in each plot was measured in $\mathrm{kg} \cdot \mathrm{ha}^{-1}$ and thousand 
Table 1. Twenty barley genotypes analyzed by molecular markers and agronomic traits

\begin{tabular}{c|l}
\hline Code & \multicolumn{1}{|c}{ Pedigree } \\
\hline 1 & SARAROOD1 \\
\hline 2 & ASTRIX(C)/3/MAL/OWB753328-5H-F1/Lignece 640 \\
\hline 3 & Srs/3/Mari/Aths*2//Arizona5908/Aths \\
\hline 4 & CERES//WI2192/EMIR/3/KAROON \\
\hline 5 & CITA”S”/4/APM/RI/MANKER/3MASVI/BON/5/COPAL”S”/6/DEIR AAL \\
\hline 6 & Giza 121/cio6248/4/APM/IB6S//11012-2-/3/API/CM67//OS/API/CM67//OS/APR/5 \\
\hline 7 & L.527//PALLIBUM1908/8 \\
\hline 8 & Walfajre/Miraj1 \\
\hline 9 & ALGER/(CI10117)/CHOYO \\
\hline 10 & Star/plaisout \\
\hline 11 & Kmk/RbriWa2196-68/3/EBC(A) \\
\hline 12 & VICTORIA/BKF Magnelone 1604/Lignece 640 \\
\hline 13 & ROBUR/MIRAJI \\
\hline 14 & WA2138-68/ILL62-19/3/ \\
\hline 15 & WALFAJR \\
\hline 16 & Piratl/Maita 1-4-3094-2 \\
\hline 17 & RANNIY/ROBUR \\
\hline 18 & Alger//WI2192/EMIR/3/KAROON \\
\hline 10 & YEA 389.3/YEA 475.4 \\
\hline 10 & \\
\hline 19
\end{tabular}

kernel weight (TKW): in grams as the weight of 1000 random wheat grain.

The experimental design was a randomized block design with three replications.

\section{DNA extraction}

Total genomic DNA was isolated according to the protocol described by Murray and Thompson (1980). Briefly, $0.5 \mathrm{~g}$ of leaf tissue per sample were ground in liquid nitrogen and incubated at $60^{\circ} \mathrm{C}$ for 20 min with $500 \mu \mathrm{l}$ of extraction buffer ( $50 \mathrm{mM}$ Tris- $\mathrm{HCl}, 60 \mathrm{mM}$ $\mathrm{NaCl}, 25 \mathrm{mM}$ EDTA, 20\% SDS) and CTAB buffer (CTAB $2 \%, \mathrm{NaCl} 0.7 \mathrm{M}$ ) in $1.5 \mathrm{ml}$ polypropylene tubes. The final DNA concentration of each sample was adjusted to $10 \mathrm{ng} / \mu \mathrm{l}$ for the RAPD and ISSR analysis.

\section{RAPD and ISSR amplification}

Briefly, PCR amplifications were carried out in a CORBETT research thermal cycler, in a reaction volume of $25 \mu \mathrm{l}$ containing $20 \mathrm{mM}$ Tris- $\mathrm{HCl}(\mathrm{pH} \mathrm{8.4)}$, $50 \mathrm{mM} \mathrm{KCl}, 2 \mathrm{mM} \mathrm{MgCl} l_{2}, 0.2 \mu \mathrm{M}$ primer, $0.1 \mathrm{mM}$
dNTP, $0.5 \mathrm{U}$ of Taq (DNA polymerase) and $30 \mathrm{ng}$ of template DNA. A total of 31 random RAPD and 20 ISSR primers were used in the current study (Table 2). Amplification reactions for RAPD primers were carried out using the following cycle profile: initial denaturation at $94^{\circ} \mathrm{C}$ for $4 \mathrm{~min}$ followed by 40 cycles at $94^{\circ} \mathrm{C}$ for $30 \mathrm{~s}$, $30-40^{\circ} \mathrm{C}$ for $15 \mathrm{~s}, 72^{\circ} \mathrm{C}$ for $90 \mathrm{~s}$ and a final 5 min extension at $72^{\circ} \mathrm{C}$. For ISSR primers, PCR reactions were performed in the following amplification conditions: initial denaturation at $94^{\circ} \mathrm{C}$ for 4 min followed by 40 cycles at $94^{\circ} \mathrm{C}$ for $30 \mathrm{~s}, 50-60^{\circ} \mathrm{C}$ for $15 \mathrm{~s}, 72^{\circ} \mathrm{C}$ for $90 \mathrm{~s}$ and a final 5 min extension at $72^{\circ} \mathrm{C}$. PCR products were separated electrophoretically in a $1.2 \%$ agarose gel in $1 \mathrm{X}$ TAE buffer and stained with ethidium bromide. The gel image was recorded using a Gel Documentation System (UVP, UK).

\section{Statistical analysis}

Two-year average values for all traits under rain-fed and irrigation conditions were calculated for further analyzes. The agronomic traits and molecular markers 
Table 2. Primers used in this study and their characteristics

\begin{tabular}{|c|c|c|c|c|c|}
\hline \multicolumn{3}{|c|}{ RAPD primers } & \multicolumn{3}{|c|}{ ISSR primers } \\
\hline Primer & Sequence $5^{\prime}-3^{\prime}$ & $\begin{array}{l}\text { Annealing } \\
\text { temperature }\end{array}$ & Primer & Sequence $5^{\prime}-3^{\prime *}$ & $\begin{array}{l}\text { Annealing } \\
\text { temperature }\end{array}$ \\
\hline OPC07 & GTCCCGACGA & 40 & UBC-880 & $($ GGAGA)3 & 53 \\
\hline $\mathrm{UBC} 18$ & GGGCCGTTTA & 30 & UBC-112 & $(\mathrm{GACA}) 4$ & 52 \\
\hline $\mathrm{T} 19$ & GTCCGTATGG & 40 & UBC-856 & (ACAC)4YG & 55 \\
\hline $\mathrm{E} 10$ & GGTGACTGTG & 40 & UBC-811 & $(\mathrm{GA}) 8 \mathrm{C}$ & 56 \\
\hline UBC31 & CCGGCCTTCC & 40 & UBC-864 & (ACTG) 4 & 53 \\
\hline UBC51 & CTACCCGTGC & 35 & UBC-855 & (AC)8YT & 56 \\
\hline UBC52 & TTCCCGGAGC & 30 & UBC-808 & $(\mathrm{AG}) 8 \mathrm{C}$ & 58 \\
\hline E17 & CTACTGCCGT & 40 & UBC-818 & $(\mathrm{CA}) 8 \mathrm{G}$ & 54 \\
\hline $\mathrm{UBC} 23$ & CCCGCCTTCC & 37 & UBC-820 & $(\mathrm{GT}) 8 \mathrm{C}$ & 58 \\
\hline U11 & AGACCCAGAG & 40 & UBC-841 & (GA)8YC & 52 \\
\hline UBC28 & CCGGCCTTAA & 31 & UBC-854 & $(\mathrm{TC}) 8 \mathrm{RG}$ & 42 \\
\hline UBC29 & CCGGCCTTAC & 40 & UBC-856 & $(\mathrm{AC}) 8 \mathrm{YA}$ & 54 \\
\hline A7 & GAAACGGGTG & 40 & UBC-872 & (GATA)4 & 33 \\
\hline $\mathrm{AB} 1$ & CCGTCGGTAG & 40 & UBC-873 & $(\mathrm{ATG}) 6$ & 58 \\
\hline OPC13 & AAGCCTCGTC & 40 & UBC-868 & $(\mathrm{GAA}) 6$ & 52 \\
\hline $\mathrm{C} 9$ & CTCACCGTCC & 35 & UBC-841 & $(\mathrm{GACAC}) 4$ & 51 \\
\hline $\mathrm{C} 16$ & CACACTCCAG & 40 & UBC-807 & $(\mathrm{AG}) 8 \mathrm{~T}$ & 53 \\
\hline $\mathrm{T} 18$ & GATGCCAGAC & 40 & UBC-809 & $(\mathrm{AG}) 8 \mathrm{G}$ & 59 \\
\hline T9 & CACCCCTGAG & 40 & UBC-857 & $(\mathrm{AC}) 8 \mathrm{~T}$ & 49 \\
\hline OPC04 & CCGCATCTAC & 40 & UBC-825 & $(\mathrm{AC}) 8 \mathrm{YG}$ & 47 \\
\hline E19 & ACGGCGTATG & 40 & & & \\
\hline D12 & CACCGTATCC & 40 & & & \\
\hline UBC9 & CCTGCGCTTA & 30 & & & \\
\hline OPC08 & TGGACCGGTG & 40 & & & \\
\hline U17 & ACCTGGGGAG & 37 & & & \\
\hline OPC15 & GACGGATCAG & 40 & & & \\
\hline UBC75 & GAGGTCCAGA & 31 & & & \\
\hline E7 & AGATGCAGCC & 40 & & & \\
\hline OPC10 & TGTCTGGGTG & 37 & & & \\
\hline E16 & GGTGACTGTG & 40 & & & \\
\hline $\mathrm{UBC} 1$ & CCTGGGCTTC & 37 & & & \\
\hline
\end{tabular}

${ }^{*} R=(A, G) ; Y=(C, T)$

were considered as the dependent variables and independent variables, respectively. In order to verify the linear relationship between independent and dependent variables, it was necessary to predict the value of the dependent variable based on the independent variable, remove those variables with negligible effect on the dependent variables and fit the best regression model. A stepwise regression was used. The probability level $(\mathrm{P})$ for rejecting any association between a marker and agronomical trait was 0.01 , so it provided informative markers with a high significance level. IBM statistics 19 software was used to perform stepwise regression analyzes. 


\section{Results and discussion}

Two-year average values for the traits under both tested conditions are presented in Table 3 . The results of stepwise regression analyzes revealed a significant association between the traits and some of the studied loci. A total of 88 informative markers, including 32 ISSR loci and 56 RAPD loci, were identified under both conditions (Table 4).

\section{Rain-fed conditions}

Several loci have been identified, accounting for a large portion of the phenotypic variation for all the traits. The number of markers associated with individual traits ranged from 2 for NSSP (number of sterile spikelets per spike) to 12 for BIO (biomass, $\mathrm{kg} \cdot \mathrm{ha}^{-1}$ ) markers. The associated markers individually explained up to $26.3 \%$ for NSSP to $53.9 \%$ for Phe (plant height, $\mathrm{cm}$ ) of the total variation appearent under rain-fed conditions (Table 4). These associated markers together explained from $44.3 \%$ NSSP to $99.7 \%$ BIO variations in the phenotypic traits examined under rain-fed conditions. Markers associated with a trait may be closely associated with one another (Wu et al., 2007).

Some of the markers were found to be associated with more than one trait. U11-750, UBC809-1200, and UBC112-1350 markers explained portions of variations in GY (grain yield, $\mathrm{kg} \cdot \mathrm{ha}^{-1}$ ) and BIO. OPC07-800 and E17-300 markers were common between SL (spike length, $\mathrm{cm}$ ) and NSPS (the number of seeds per spike). Another informative marker, E16-1300, was found to be effective in Phe and TKW (thousand kernel weight, g). Such associations may be due to the pleiotropic effects of the linked markers on different traits (Meredith and Bridge, 1971; Culp et al., 1979; Basaki et al., 2011). U11-750 marker has a relatively great role in the variation of GY and BIO; thus, it would be interesting to perform selection of GY and BIO under drought stress.

\section{Irrigation conditions}

The results of a stepwise regression analysis revealed significant associations between the traits and some of the studied loci under irrigated conditions (Table 4). More than one informative marker was identified for all of the studied traits. A significant association with at least one of the 7 traits under irrigated conditions was observed for 32 of the 147 polymorphic markers. The number of markers associated with individual traits ranged from 3 (TKW, NSSP, Phe) to 7. GY, SL, BIO and NSPS regressed on as many as 7 markers (Table 3). Some markers were found to be responsible for more than one trait; for example, marker E17-1350 showed associations with GY and BIO. The UBC856-1400 marker was the second most powerful marker selected by multiple regression analysis and was significantly associated with GY and Phe. The UBC872-1700 marker was shared between SL and GY.

\section{Stable informative markers across two environments}

There was a low association for the expression of the informative markers between the two tested environmental conditions. As Quarrie et al. (2005) stated, this may be a result of the preferential expression of QTL under drought stress conditions. However using multiple regressions, OPC4-1050 (GY), E17-400 (BIO), and E191100 (SL) markers were found to be associated with individual traits under both conditions; they were more stable and consistent across the two environments. These markers were, therefore, considered to be relatively more reliable (Table 4). Hopefully, some of these informative markers can be separated by gel electrophoresis and considered candidate markers for scanning the genome for related agronomical traits, mapping and finally breeding programs. Also, SCAR (sequence characterized amplified regions) markers can be obtained from sequenced informative marker fragments for use in marker assisted selection (MAS) (Ruan et al., 2009).

Among the RAPD primers, special attention should be drawn to primer E17, which had the highest number of fragments associated with BIO, Phe, SL, NSPS and TKW traits under rain-fed conditions. Moreover, ISSR primer UBC856 revealed loci associated with GY, Phe and NSSP traits under irrigated conditions. Pasqualone et al. (2000) found that the UBC-856 primer is one of the most polymorphic ISSR primers to study genetic diversity in durum wheat.

\section{Conclusions}

Informative fragments could be successfully cloned and sequenced and used as polymorphic diagnostic tools. It is to be hoped that some of these markers will be used for MAS in future barley breeding programs. In a breeding program, crossings between more genetically dis- 
Table 3. Two-year average values for the traits under rain-fed and irrigation conditions

\begin{tabular}{|c|c|c|c|c|c|c|c|c|c|c|c|c|c|c|}
\hline \multirow{2}{*}{$\begin{array}{l}\text { Genotype } \\
\text { code }\end{array}$} & \multicolumn{2}{|c|}{$\begin{array}{l}\text { Grain yield } \\
{\left[\mathrm{kg} \cdot \mathrm{ha}^{-1}\right]}\end{array}$} & \multicolumn{2}{|c|}{$\begin{array}{l}\text { Biomass } \\
{\left[\mathrm{kg} \cdot \mathrm{ha}^{-1}\right]}\end{array}$} & \multicolumn{2}{|c|}{$\begin{array}{l}\text { Plant height } \\
{[\mathrm{cm}]}\end{array}$} & \multicolumn{2}{|c|}{$\begin{array}{l}\text { Spike length } \\
{[\mathrm{cm}]}\end{array}$} & \multicolumn{2}{|c|}{$\begin{array}{l}\text { Number of seed } \\
\text { per spike }\end{array}$} & \multicolumn{2}{|c|}{$\begin{array}{l}\text { Number of sterile } \\
\text { spikelets per spike }\end{array}$} & \multicolumn{2}{|c|}{$\begin{array}{c}\text { Thousand Kernel } \\
\text { weight }[g]\end{array}$} \\
\hline & irrigation & rain-fed & irrigation & rain-fed & irrigation & rain-fed & irrigation & rain-fed & irrigation & rain-fed & irrigation & rain-fed & irrigation & rain-fed \\
\hline 1 & 6293.05 & 4517.77 & 17034.25 & 10753.40 & 60.17 & 56.64 & 5.22 & 5.69 & 25.29 & 32.50 & 4.00 & 8.66 & 41.32 & 35.33 \\
\hline 2 & 5691.96 & 2431.05 & 15020.33 & 9624.06 & 57.50 & 55.68 & 4.49 & 4.65 & 28.77 & 27.82 & 5.70 & 11.20 & 41.05 & 35.10 \\
\hline 3 & 6447.04 & 4561.23 & 16661.54 & 11894.18 & 59.51 & 49.74 & 5.17 & 5.74 & 37.28 & 36.40 & 6.70 & 5.83 & 40.38 & 29.63 \\
\hline 4 & 6740.11 & 4252.33 & 16336.08 & 11189.39 & 65.08 & 57.51 & 4.67 & 5.22 & 34.46 & 28.70 & 10.00 & 6.98 & 40.48 & 35.01 \\
\hline 5 & 5529.25 & 3074.35 & 16666.40 & 10088.57 & 63.64 & 57.57 & 4.97 & 4.81 & 27.18 & 32.27 & 4.05 & 8.61 & 40.01 & 34.99 \\
\hline 6 & 8633.67 & 4267.84 & 20012.73 & 12662.77 & 53.97 & 45.90 & 5.11 & 4.78 & 42.10 & 40.51 & 6.21 & 9.40 & 36.95 & 30.08 \\
\hline 7 & 6139.39 & 3276.32 & 16847.61 & 12153.47 & 59.61 & 54.30 & 4.91 & 4.77 & 39.12 & 33.37 & 6.64 & 8.24 & 39.89 & 31.40 \\
\hline 8 & 6321.33 & 4133.83 & 14841.85 & 11909.49 & 64.01 & 64.74 & 4.55 & 5.48 & 39.78 & 32.92 & 9.43 & 7.44 & 41.77 & 31.86 \\
\hline 9 & 6627.33 & 3764.90 & 15722.44 & 10113.13 & 62.61 & 51.63 & 4.24 & 4.58 & 39.75 & 35.64 & 7.23 & 8.38 & 35.59 & 25.42 \\
\hline 10 & 6180.04 & 3318.19 & 14613.70 & 11555.40 & 58.92 & 55.43 & 4.36 & 5.87 & 33.51 & 34.80 & 7.04 & 7.74 & 40.39 & 29.24 \\
\hline 11 & 6128.12 & 3602.05 & 16387.00 & 11521.57 & 68.02 & 52.06 & 4.90 & 5.54 & 40.03 & 31.03 & 9.48 & 6.83 & 42.18 & 29.69 \\
\hline 12 & 6157.01 & 3760.04 & 17187.00 & 10216.28 & 55.85 & 53.86 & 5.29 & 5.16 & 37.24 & 29.05 & 10.20 & 8.75 & 39.44 & 30.06 \\
\hline 13 & 6237.35 & 4183.85 & 15143.53 & 11463.43 & 58.40 & 52.28 & 4.61 & 5.00 & 26.39 & 26.85 & 6.06 & 9.60 & 41.87 & 30.33 \\
\hline 14 & 8080.63 & 3673.17 & 17927.94 & 9967.70 & 57.21 & 58.05 & 5.18 & 6.36 & 38.94 & 24.76 & 8.40 & 6.72 & 36.93 & 32.67 \\
\hline 15 & 5833.85 & 3775.91 & 16155.18 & 11391.26 & 59.80 & 62.05 & 5.82 & 5.80 & 31.06 & 30.26 & 4.44 & 9.93 & 41.86 & 34.19 \\
\hline 16 & 6689.96 & 3906.76 & 16983.65 & 13166.72 & 65.28 & 54.59 & 5.77 & 5.97 & 37.23 & 30.84 & 5.39 & 7.71 & 37.51 & 27.65 \\
\hline 17 & 6665.70 & 3844.44 & 17282.74 & 10235.68 & 59.90 & 57.35 & 4.40 & 5.68 & 32.99 & 27.18 & 7.38 & 10.10 & 38.16 & 30.94 \\
\hline 18 & 6867.80 & 4026.46 & 18119.74 & 11004.32 & 65.19 & 56.31 & 5.46 & 6.77 & 25.98 & 18.58 & 5.58 & 3.56 & 41.45 & 34.40 \\
\hline 19 & 6472.20 & 4721.52 & 16420.01 & 10401.94 & 70.17 & 57.27 & 6.61 & 6.93 & 29.09 & 26.46 & 7.40 & 8.91 & 40.12 & 32.99 \\
\hline 20 & 6546.20 & 3321.85 & 15721.80 & 9856.47 & 56.97 & 47.30 & 5.31 & 5.54 & 35.72 & 32.53 & 9.66 & 7.83 & 38.04 & 29.94 \\
\hline
\end{tabular}

GY - grain yield $\left(\mathrm{kg} \cdot \mathrm{ha}^{-1}\right)$, Phe - plant height $(\mathrm{cm}), \mathrm{SL}$ - spike length $(\mathrm{cm})$, NSPS - number of seeds per spike, NSSP - number of sterile spikelets per spike, BIO - biomass $\left(\mathrm{kg} \cdot \mathrm{ha}{ }^{-1}\right)$,

TKW - thousand kernel weight (g) 
Table 4. Result of the stepwise regression analysis for molecular markers and agronomic traits

\begin{tabular}{|c|c|c|c|c|c|c|c|c|}
\hline Traits & Conditions & $\begin{array}{l}\text { Number } \\
\text { of informative } \\
\text { markers }\end{array}$ & Informative markers* & $\begin{array}{c}R^{2} \\
\text { adjusted } \\
{[\%]}\end{array}$ & $\begin{array}{l}\text { Main marker } \\
\text { with highest } \\
\qquad R^{2}\end{array}$ & $\begin{array}{l}\text { B } \\
\text { (regression } \\
\text { coefficient) }\end{array}$ & $\begin{array}{c}P \\
\text { value }\end{array}$ & $\begin{array}{c}R^{2} \\
\text { changed }\end{array}$ \\
\hline \multirow{2}{*}{ GY } & rain-fed & 7 & $\begin{array}{l}\text { U1 1-750, UBC9-1350,OPC4-1050, UBC841-400, UBC809-1200, } \\
\text { UBC18-750, UBC112-1350 }\end{array}$ & 94.2 & U11-750 & -446.75 & .000 & 0.522 \\
\hline & irrigated & 7 & $\begin{array}{l}\text { E17-1350, UBC1-1300, UBC856-1400, OPC4-1050, UBC872-1700, } \\
\text { UBC112-1320, UBC18-1700 }\end{array}$ & 94.1 & $\mathrm{E} 17-1350$ & -1925.63 & .000 & 0.473 \\
\hline \multirow[t]{2}{*}{$\mathrm{BIO}$} & rain-fed & 12 & $\begin{array}{l}\text { UBC9-800, U11-750, UBC854-1350, E17-400, UBC854-920, } \\
\text { OPC4-650, UBC841-450, OPC07-1000, UBC841-1200, } \\
\text { UBC809-1200, UBC112-1350, UBC28-1100, }\end{array}$ & 99.7 & UBC9-800 & -1948.967 & .000 & 0.280 \\
\hline & irrigated & 7 & $\begin{array}{l}\text { E17-1350, OPC13-600, C16-1200, E17-400, E17-1300, UBC808-805, } \\
\text { UBC854-250 }\end{array}$ & 95.9 & $\mathrm{E} 17-1350$ & -3470.736 & .000 & 0.414 \\
\hline \multirow{2}{*}{ Phe } & rain-fed & 6 & E16-1300, UBC51-800, U11-700, T9-920, T9-1400, E17-400 & 95.3 & E16-1300 & 4.360 & .000 & 0.539 \\
\hline & irrigated & 3 & UBC856-1400, C16-1000, UBC28-1150 & 66.6 & UBC856-1400 & -3.889 & .005 & 0.389 \\
\hline \multirow{2}{*}{ SL } & rain-fed & 8 & $\begin{array}{l}\text { E19-1100, OPC07-800, OPC4-650, UBC75-500, UBC51-950, } \\
\text { OPC15-1200, E17-300 }\end{array}$ & 95.9 & E19-1100 & -.995 & .000 & 0.509 \\
\hline & irrigated & 7 & $\begin{array}{l}\text { E19-1100, UBC873-1250, UBC868-900, UBC841-800, E10-2250, } \\
\text { A7-700, UBC872-1700 }\end{array}$ & 95.1 & E19-1100 & -.940 & .000 & 0.552 \\
\hline \multirow{2}{*}{ NSPS } & rain-fed & 8 & $\begin{array}{l}\text { OPC07-800, C16-1200, UBC872-700, E10-1200, C9-1050, E17-300, } \\
\text { T9-920, E17-900 }\end{array}$ & 96.7 & A7-700 & 7.944 & .000 & 0.337 \\
\hline & irrigated & 7 & $\begin{array}{l}\text { OPC07-1050, UBC855-1000, UBC18-1600, OPC10-800, } \\
\text { UBC811-1450, UBC854-1100, UBC856-700 }\end{array}$ & 95.6 & OPC07-1050 & 8.113 & .000 & 0.410 \\
\hline \multirow{2}{*}{ NSSP } & rain-fed & 2 & UBC873-630, A7-700 & 44.3 & UBC873-630 & -3.261 & .003 & 0.263 \\
\hline & irrigated & 3 & UBC857-650, UBC811-2200, UBC864-400 & 57.5 & UBC857-650 & -3.013 & .000 & 0.288 \\
\hline \multirow[t]{2}{*}{ TKW } & rain-fed & 8 & $\begin{array}{l}\text { OPC15-1200, E16-1300, UBC855-570, UBC864-400, E17-900, } \\
\text { D12-2000, OPC13-600, E19-550 }\end{array}$ & 96.0 & OPC $15-1200$ & 10.572 & .000 & 0.389 \\
\hline & irrigated & 3 & U17-800, OPC07-650, UBC28-750 & 71.5 & $\mathrm{U} 17-800$ & -3.013 & .000 & 0.419 \\
\hline
\end{tabular}

*Numbers on the right indicate fragment sizes in the base pair 
tant individuals will increase the chance of transgressive segregation in their progeny. Therefore, these markers could be used to choose parents for the development of mapping populations. RAPD primer E17 and ISSR primer UBC856 had the highest number of fragments associated with the traits under rain-fed and irrigated conditions, respectively. These primers have been found to be useful for the study of genetic diversity and for association analyzes in barley. Stable and consistent markers identified across the two environments can be separated by gel electrophoresis and considered candidate markers for scanning the genome for related agronomical traits.

\section{References}

Basaki T., Choukan R.M., KhayamNekouei S., Mardi M., Majidi E., Faraji S., Zeinolabedini M. (2011) Association analysis for morphological traits in pomegranate (Punicageranatum L.) using microsatellite markers. Middle East J. Sci. Res. 9(3): 410-417.

Chowdhry M.A., Rasool I., Khaliq I., Mahmood T., Gilani M.M. (1999) Genetics of some metric traits in spring wheat under normal and drought environment. Rachis. Newslett. 18(1): 34-39.

Culp T.W., Harrell D.C., Kerr T. (1979) Some genetic implications in the transfer of high fiber strength genes to upland cotton. Crop Sci. 19: 481-484.

Emam Y. (2007) Cereal production. Shiraz Univ. Press.

Firoozi B., Sofalian O., Shokrpour M., Rasoulzadeh A., Ahmadpoor F. (2012) Assessment of drought tolerance indices and their relation with ISSR markers in bread wheat (Triticum aestivum L.). Not. Sci. Biol. 4(3): 143-150.

Gebhardt C., Ballvora A., Walkemeier B., Oberhagemann P., Schuler K. (2004) Assessing genetic potential in germplasm collections of crop plants by marker-trait association: A case study for potatoes with quantitative variation of resistance to late blight and maturity type. Mol. Breed. 13: $93-102$.

Gomez K., Gomez A.A. (1984) Statistical procedures for agricultural research. John Wiley, New York, USA.

Henshall J.M., Goddard M.E. (1995) QTL detection using multiple regression on average transmission probabilities. Proc. Assoc. Advmt. Anim. Breed. Genet. 13: 219-222.

Meredith A., Bridge R.R. (1971) Breakup of linkage block in cotton, Gossypium hirsutum L. Crop Sci. 11: 695-697.

Murray M.G., Thomson W.F. (1980) Rapid isolation of high weight plant DNA. Nucl. Acids Res. 8: 4321-4325.
Pasqualone A., Lotti C., Bruno A., De Vita P., Di Fonzo N., Blanco A. (2000) Use of ISSR markers for cultivar identification in durum wheat. [in:] Durum wheat improvement in the Mediterranean region: New challenges. Ed. Royo C., Nachit M., Di Fonzo N., Araus J.L. CIHEAM, Zaragoza 2000: 157-161 (Options Méditerranéennes: Série A Séminaires Méditerranéens; n. 40).

Quarrie S.A., Steed A., Calestani C., Semikhodskii A., Lebreton C., Chinoy C., Steele N., Pljevljakusic D., Waterman E., Weyen J. et al. (2005) A high-density genetic map of hexaploid wheat (Triticum aestivum L.) from the cross Chinese Spring X SQ1 and its use to compare QTLS for grain yield across a range of environments. Theoret. Appl. Genet. 110(5): 865-880.

Rakshit A., Rakshit S., Singh J., Chopra S.K., Balyan H.S., et al. (2010) Association of AFLP and SSR markers with agronomic and fibre quality traits in Gossypium hirsutum L. J. Genet. 89: 155-162.

Ruan C.J., Li H., Mopper S. (2009) Characterization and identification of ISSR markers associated with resistance to dried-shrink disease in sea buckthorn. Mol. Breed. 24(3): 255-268.

Salem Farag K.F.M. (2004) The inheritance and molecular mapping of genes for post-anthesis drought tolerance (PADT) in wheat. M. Sc. Thesis. El-Menoufia, Ägypten.

Schulman A.H. (2007) Molecular markers to assess genetic diversity. Euphytica 158: 313-321.

Sofalian O.S.A., Mohammadi S., Aharizad M., Moghaddam, Shakiba M.R. (2008) Mapping of QTLs for frost tolerance and heading time using SSR markers in bread wheat. Afr. J. Biotechnol. 9(20): 5260-5264.

Stuber C.W., Polacco M., Senior M.L. (1999) Synergy of empirical breeding, marker assisted selection and genomics to increase crop yield potential. Crop Sci. 39: 1571-1583.

Welsh J., McClelland M. (1990) Fingerprinting genomes using PCR with arbitrary primers. Nucl. Acids Res. 18: 72137218.

Williams J.G.K., Kubelik A.R., Livak K.L., Rafalski J.A., Tingey S.V. (1990) DNA polymorphisms amplified by arbitrary primers are useful as genetic markers. Nucl. Acids Res. 18: 6531-6553.

Wu J., Jenkins J.N., Mc Carty J.C., Zhong M., Swindle M. (2007) AFLP marker associations with agronomic and fiber traits in cotton. Euphytica 153: 153-163.

Zietkiewicz E., Rafalski A., Labuda D. (1994) Genome fingerprinting by simple sequence repeat (SSR)-anchored polymerase chain reaction amplification. Genomics 20: 176183. 